\title{
COLOUR AND GENDER: LANGUAGE NUANCES
}

\author{
COLOR Y GÉNERO: MATICES DEL LENGUAJE
}

\author{
Isabel ESPINOSA-ZARAGOZA ${ }^{1}$
}

\section{Author / Autora:}

Isabel Espinosa-Zaragoza

Universidad de Alicante

Alicante, Spain

Isabel.espinosa@ua.es

https://orcid.org/0000-0002-9206-6917

Submitted / Recibido: 01/11/2020

Accepted / Aceptado: 10/04/2021

To cite this article / Para citar este artículo: Espinosa-Zaragoza, I. (2021). Colour and gender: language nuances. In Feminismo/s, 38, 115-147. Women, Sexual Identity and Language [Monographic dossier]. I. Balteiro (Coord.). https://doi.org/10.14198/ fem.2021.38.05

\section{Licence / Licencia:}

This work is licensed under a Creative Commons Attribution 4.0 International.

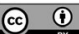

(C) Isabel Espinosa-Zaragoza

\begin{abstract}
It is a deeply rooted belief that women possess a richer colour vocabulary than men (Rich, 1977). According to Lakoff, certain adjectives denoting colour (e.g. mauve) would never be naturally chosen by men unless they were «imitating a woman sarcastically, or a homosexual, or an interior decorator» (1973, p. 49). Are these affirmations adjusted to our present reality? Nowadays, colour is present in almost every economic sector. Consequently, a proficient use of colour vocabulary is expected from professionals, regardless of their gender. Hence, if the differences in colour vocabulary are learnt and highly dependent on the user's necessities and expectations, then said differences after globalisation and exposure to the Internet should not be so striking. With this objective in mind, this study analyses colour elicitation performed by university students. Both their descriptive capacity and colour lexicon availability are measured depending
\end{abstract}

1. The author of this paper is the beneficiary of a contract from the Vicerrectorado de Investigación y Transferencia de Conocimiento/ Vice President for Research and Knowledge Transfer of the University of Alicante for pre-doctoral training (from 01/01/2019 to 31/12/2021). This research has been carried out with the financing obtained in the aforementioned contract. 
on students' colour terms usage. Furthermore, potential reasons for variation are provided.

Keywords: gender stereotypes; sociolinguistics; colour terminology; colours; gender differences.

\section{Resumen}

Es una creencia profundamente arraigada que las mujeres poseen un vocabulario de colores más rico que los hombres (Rich, 1977). Según Lakoff, ciertos adjetivos que denotan color (por ejemplo, malva) nunca serían elegidos espontáneamente por los hombres a menos que estuvieran «imitando sarcásticamente a una mujer, a un homosexual o a un decorador de interiores» (1973, p. 49). ¿Se ajustan estas afirmaciones a nuestra realidad actual? Hoy en día el color está presente en casi todos los sectores económicos. En consecuencia, se espera un uso competente del vocabulario de colores por parte de los profesionales, independientemente de su género. Por lo tanto, si las diferencias en el vocabulario de los colores se aprenden y dependen en gran medida de las necesidades y expectativas del usuario, dichas diferencias después de la globalización y la exposición a Internet no deberían ser tan notables. Con este objetivo en mente, este estudio analiza la elicitación del color realizada por estudiantes universitarios. Tanto su capacidad descriptiva como la disponibilidad de léxico de colores se miden según el uso de los términos de color de los estudiantes. Además, se proporcionan posibles razones para la variación.

Palabras clave: estereotipos de género; sociolingüística; terminología de color; colores; diferencias de género.

\section{INTRODUCTION}

Colour terms are linguistic signs assigned to certain visual stimuli that could be arranged in enclosed colours spaces or macro-categories. Undoubtedly, the study of colour will always be interdisciplinary owing to its ubiquitous nature. It involves different areas of knowledge, such as vision and perception, symbolism and meaning, colour associations and emotions, colour categorization, among many others.

A plethora of diverse and divergent occupations and areas of life entail colour knowledge: photographers, videographers, illustrators, painters, makeup artists, fashion designers, interior designers, graphic and web designers, floral designers, teachers, or even bakers require a certain level

Feminismo/s 38, July 2021, 115-147 
of colour acquaintance. Although language for specific purposes acknowledges different colour terms depending on the industry they belong to (e.g. automobile sector (Bergh, 2007), cosmetics and selfcare (Wyler, 1992; Skorinko et al., 2006, Merskin, 2007), fashion (Stoeva-Holm, 2007), winery (Mioduszewska, 2014), etc.), its pervasiveness may be unconsciously and unintentionally contributing to enlarging our colour lexicon.

Nowadays, colour terms are used as a marketing technique to appeal to the consumer, hence the great attention and detail put into their creation. Some of them even exude wordplay meant to spark a smirk and interest in the consumer (Obregón, 1978; Biggam, 2012) or reach extravagant extremes with fancy-sounding colour nomenclatures that do not help form a prototypical hue in our minds (Wyler, 1992; Biggam, 2012). We are constantly exposed to fancy-sounding colour terms through advertising and other culture-related tasks -such as one's job, hobbies and interests- which ultimately might conform and integrate a different sized colour vocabulary: one where the colour spectrum is divided into more spaces, and therefore, more colour labels.

Traditionally, females are deemed as highly proficient at naming and identifying colours (Ligon, 1932; DuBois, 1939; Rich, 1977; Swaringen et al., 1978; Steckler \& Cooper, 1980; Nowaczyk, 1982; Simpson \& Tarrant, 1991; Elias et al., 2003; Mylonas et al., 2014), although the literature covering those topics has sometimes been based on impressionistic introspections and linguistic intuitions (Lakoff, 1973; Conklin, 1974; Kramer, 1974). Colour proficiency was regarded as shallow and nonimportant matter, relegated to females far from positions of power (Lakoff, 1973, p. 49). After 50 years of advances towards gender equality, should said differences be still prevalent, new reasons must be provided to try to clarify and justify sex-related differences, if any. To do so, this study focuses on colour elicitation tasks performed by Spanish college students.

In the following sections the types of colour names will be introduced, along with gender differences and sociocultural variables that would account for such differences in colour lexicon. Then, the objectives and methodology will be explained, followed by the analysis of results and discussion and, finally, some conclusions. 


\section{COLOUR TERMINOLOGY}

Colour is a three-dimensional continuum (i.e. hue, lightness and saturation) and when in need of determining its limits, categorizations are resorted to, that is, labels that delimit the beginning and end of colour spaces within the continuum. «Colour naming relies on the recording of sensory information about an abstract colour or the colour of an object and its expression through the medium of language» (Mylonas \& Macdonald, 2012, p. 256). «Basic colour term»-henceforth BCTs- (Berlin \& Kay, 1969), «the big names for colours», «the base of the colours» or «the mothers of colours» (Kuschel $\&$ Monberg, 1974, p. 218) are some of the denominations assigned to the broad colour categorizations that are first learnt at school: white, black, red, yellow, blue, green, pink, orange, brown, purple and grey. In words of Stoeva-Holm (2007, p. 428): «BCTs are the oldest color terms. They have a certain place in human language and the acquisition of them takes place in childhood». Consequently, BCTs are macro-categories that cover a wide colour range in the colour spectrum (Stoeva-Holm, 2007), considerably wider than non-basic colour terms, which are more specific (for example, when it comes to the colour blue, navy and turquoise are terms that fall are under the umbrella of the term «blue», but not all «blues» are navy nor turquoise). All BCTs are characterised by their (1) multi-purposefulness and applicability to several contexts (thus, blonde and brunette cannot be BCTs), (2) unique hyperonymous status, that is, they are not considered a variation or specification of other colours (e.g. crimson is a kind of red) and (3) salience, their prominence in lexical availability. Conversely, BCTs can also be defined according to what they are not: they are not (4) context-specific terms, (5) nor compounds (e.g. blue-green), (6) nor polymorphemic (e.g. pinkish), in other words, made up of a single morpheme unmarked by inflections or marked morphemes (i.e. monomorphemic). Peninsular Spanish BCTs coincide with the English BCTs (see Lillo et al., 2018)².

Non-basic colour terminology, often referred to as «non-basic terms» (Anishchanka et al., 2014; Biggam, 2014, p. 9), «fancy name» (Skorinko et al., 2006) or «Elaborate Colour Terms» (Steinvall, 2002) -henceforth ECTs-,

2. Mexican Spanish and Uruguayan Spanish also include celeste «sky blue,» café «brown,» and violeta "purple» (Lillo et al., 2018, p. 1). 
could be considered as a more 'sophisticated' one, acquired with time and, especially, with exposure to colour-related contexts (e.g. graphic design, cosmetics, fashion, photography and others). Non-basic terms present three different types: compositional, consisting of a BCT as head of the compound and premodified by an adjective specifying lightness ${ }^{3}$ (e.g. light blue, medium red, dark pink) or its prototypicality (true red, classic red); non-compositional, such as navy, forest, maroon or mauve; and idiosyncratic colour terms, for instance, woodland green, barolo red or summit white, much more marketing oriented (Anishchanka et al., 2014). All of these types sharing a more restricted referential range of colour than BCTs (i.e. forest is a type of green, a hyponym, but non-compositionals being more flexible to cross boundaries or with fuzzier limits than compositionals. Thus, light blue is well-defined and delimited within a BCT category, as a blue with low saturation, but navy expands from blue to purple or even black.

In the same way, Casson's (1994) secondary colour terms are colour terms created through metonymy («entity stands for the entity's colour»), where colour denotation is conveyed through allusion to focal reference points, to prototypical objects. Therefore, «colors are perceived as properties of objects and metonymically conceptualized as physical entities» (Casson, 1994, p. 17). In this way, these terms rely heavily on physical experience with objects, entities and realities and yield a prototypical mental image of the coloured object as a cognitive focal point.

[...] colour names such as ruby red, brick red or sky blue can be thought of as evoking dual cognitive reference points. By itself, a term like red or blue evokes a focal colour, which in turn evokes the more inclusive region in colour space that it anchors. A noun such as ruby, brick or sky names an entity that not only has a characteristic colour but is sufficiently familiar to serve as a reference point. From these two reference points, we compute the desired notion: red tells us that brick is to be construed with respect to its colour, and brick directs our attention to a particular location within the red region. (Mioduszewska, 2014, p. 341)

3. Personally, I would also include within compositional terms the ones modified by a term indicating colour saturation (e.g. intense, vivid, pure, true, pale, etc.), hue (reddish orange) and temperature (e.g. cool, warm). 
This relationship is not metaphorical but metonymic, as it is not imagined but real: «While metaphors involve an imagined link between two concepts, metonyms involve a real link. [...] metonyms require a certain amount of shared knowledge in order to convey the desired message.» (Biggam, 2012, p. 49). These metonymic colour terms, -MCTs for short-, (e.g. ruby red, brick red, sky blue) are subject to eluding the BCT of the compound leading to a non-compositional colour term (e.g. ruby, brick, sky) and can be organised according to the theme or semantic field where they belong: plants and flowers (e.g. rose, chestnut), nature (e.g. sea, forest), animals (e.g. teal, sepia), minerals (e.g. ruby, charcoal), food (e.g. chocolate, peach) and objects (e.g. denim, brick).

A step further are idiosyncratic colour terms: «creative color names that are typically developed in advertising but are hardly used outside the marketing context», as for example summit white, woodland green and barolo red, colour terms found exclusively in the automobile industry (Anishchanka et al., 2014, p. 337). Accordingly, these idiosyncratic colour terms could be considered closer to neologisms or market-driven ad-hoc formations due to the intended suggestiveness, originality, distinctiveness and poetic nature they offer rather than salience. Although unlikely in everyday use, the distribution of this type and the rest of colour terminology is unbalanced as far as gender is concerned.

\section{GENDER DIFFERENCES IN COLOUR LEXICON}

Early colour studies at the beginning of the $20^{\text {th }}$ century already pointed to gender differences in colour terminology (Ligon, 1932; DuBois, 1939; Rich, 1977). There is extensive literature on gender differences on colour preference (Ling et al., 2006; Hurlbert \& Ling, 2007; Hurlbert \& Ling, 2016), on colour perception, especially, regarding the grue region (i.e. blue-green) (Brown \& Lindsey, 2004; Fider \& Komarova, 2019), promptness in stimuli to colour term match (Ligon, 1932; DuBois, 1939), description of colour terms (Nowaczyk, 1982), or size of colour vocabulary (Steckler \& Cooper, 1980; Nowaczyk, 1982; Simpson \& Tarrant, 1991; Gekousidou \& Iliadou, 1997; Bonnardel et al, 2002; Mylonas et al., 2014), amongst others. 
Specifically, female proficiency and outperformance colour-wise when compared to males has been widely researched on. A richer, fine-grained colour vocabulary and faster responses (i.e. access to colour lexicon) in females is made evident through an array of different experiments carried out in the last 50 years throughout different countries (Rich, 1977; Swaringen et al., 1978; Steckler \& Cooper, 1980, Nowaczyk, 1982; Simpson \& Tarrant, 1991; Saucier et al., 2002; Elias et al., 2003; Ellis et al., 2008; Mylonas et al., 2014).

Some of these studies differ methodologically in the means of colour presentation to participants. For instance, Steckler and Cooper (1980) tested colour lexicon verbal skills through pictures showing unisex real-world objects (i.e. sweaters). Among the colours selected, 8 out of the 11 were BCTs worn by different male and female models with similar traits (including height, complexion, eye and hair colour, clothing, etc.). Their results attested that women used more specific colour terms (e.g. specifically, MCTs related to food), whereas men preferred premodification (e.g. saturation adjectives) and BCT compounds. However, this approach does not take into account the possibility of underlying contextual information -the fashion industry and its known fancier use of colour terminology-swaying the participants' elicitation.

Similarly, Gekousidou and Iliadou (1997) tested Greek colour production in university graduates by selecting traditionally male (cars and clothing) and female related objects (cosmetics and clothing), as well as neutral objects (food, unisex apparel, stationery, electronics and accessories) in magazine pictures. Likewise, the existence of these items within a particular context might have swayed and misled the participants into answering a particular, more elaborate colour terminology characteristic of marketing. For instance, the authors exemplify a case in which a facial cream evoked terms such as pink and cream, possibly influenced by the product itself or an ice-cream not eliciting the term turquoise, as shades of blue are not typically associated with edible entities (1997, p. 95-96). As a consequence, contextual information might have influenced a more specific colour terminology attributed to certain areas of expertise. Regardless of that fact, in that study «women tended to place emphasis on distinctiveness, while men emphasized similarity» 
(1997, p. 97). In other words, females favour more specific and precise terminology within the colour spectrum, whereas males show preference for qualified terms, which occupy a wider space in the colour continuum.

In addition, it is important to reflect on whether or not the chromatic terminology in advertisements is evenly directed at consumers. Several clothing catalogues were analysed (i.e. women's clothing only, males clothing only and general merchandise) in Frank's (1990) study in order to determine if colour terms were differently curated depending on gender in clothing advertisements. Colour terms were grouped into two types: «conventional colour terms» (BCTs and MCT+BCT such as canary yellow or forest green) and «non-traditional ones» (watermelon, seafoam, hibiscus). The results reveal a wider variety of colour terminology to describe female clothing, especially in colours red, white and purple. A likely explanation is that this dissimilar exposure influences gender differences in colour lexicon. As, in this case, the colour terminology is within an advertising context -not the actual use of consumers, but what is directed at them-, the plethora of colour terms may only be executed to force a sense of novelty, to appeal the consumer and/or to emphasise the differences among textile dyes. Hence, the terminology in this study, which includes terms such as iced pink and petal pink, «merely reflects a cultural bias which already exists: 'women's colors' are complex, multi-varied, more abstract, and expressive (raspberry sorbet, daffodil yellow, blush) while 'men's colors' are simple, straightforward, conventional, realworld (royal blue, gold, grey)» (Frank, 1990, p. 123). This leads to believe that exposure to those linguistic constructions might induce the reader of the intended clothing pieces to acquire and store such terminology in their memory. Thus, it would explain why women adopt a wider variety of MCTs and males more BCTs and qualified terms.

Another study with college students by Nowaczyk (1982) consisted of two experiments: (1) providing colour terms to stimuli and describing non-basic colour terms and (2) matching colour words to visual stimuli. In order to avoid methodological flaws, like men possessing same colour lexicon as women but being reluctant to use it, Nowaczyk (1982) actively encouraged to avoid colour term repetition in the former test. His findings reveal interesting differences in colour vocabulary production. On the one 
hand, males show lesser ability to generate colour words, that is, to access the labels or produce them, but not an inability to use them or recognize them. Apart from that, they are more likely to use BCTs even when provided with a list of colour terms that have to be matched to colour stimuli. On the other hand, not only did women describe more terms than men but also provided more elaborate descriptions. As a consequence, high accuracy is exhibited on the females' side, who excel with greater number of MCTs.

Traditionally, all previous experiments were performed in situ with colour chips, where lighting conditions were not always properly controlled or with pictures of real objects which could potentially elicit context specific terminology. Conversely, Mylonas et al. (2014, p. 236) took a different approach and tested colour vocabulary in different languages via a lighting-controlled context-free online environment: hues shown against a neutral background to which participants must assign a term. Their results are congruent with previous in-person studies, such as those of Ligon (1932), DuBois (1939), Rich (1977), Swaringen et al. (1978), Nowaczyk (1982), Frank (1990), Simpson \& Tarrant (1991) and Saucier et al. (2002).

Specifically, women offer more often hyponyms of BCTs (e.g. pastel rose, vanilla, olive) whereas men tend to use a combination of the BCTs (e.g. bluegreen, purplish blue) or BCTs with modifiers (e.g. dark purple, pale orange, vivid green). Also, women segment the colour space linguistically more densely: e.g. an area named orange and brown by men is differentiated in women's naming into orange, salmon, peach, salmon pink, beige and tan. (Mylonas et al., 2014, p. 19-20)

Finally, when taking into account variables such as age, hobbies and profession, a number of studies are worth mentioning. Simpson and Tarrant's (1991) results affirm that older participants excel at elaborate use of colour terms, regardless of sex, which is an obvious sign of vocabulary increase due to experience and exposure. Additionally, colour-related hobbies correlated significantly with enhanced colour vocabulary, but only in men. Similarly, Swaringen et al. (1978) tested colour production with college students and the study points to a higher number of leisure activities related to colour in females which could explain their proficiency. Along this line, Rich's (1977) results also demonstrate that women showcase a richer colour lexicon than men. Interestingly, nuns scored less than the rest of women but still 
exhibited better results than men, even though they are known to reject a 'normal life' to stick to a more 'modest' one away from materialistic commodities. Nevertheless, her study offers other surprising results, such as younger males presenting a better colour lexicon than older men, which disputes the argument of exposure and experience as a path to competence and mastery.

In sum, this section has attempted to provide a brief summary of the literature relating to gender differences in colour terminology. Regardless of the means of colour presentation, age, profession, nationality and socio-economical context, a more proficient colour use is usually made evident by female participants. The next section attempts to summarise some of the argumentations which would explain said differences.

\section{FACTORS ACCOUNTABLE FOR GENDER DIFFERENCES IN COLOUR NAMING}

Several culture-related argumentations that would explain significant differences in colour lexicon have been put forward over the years, although chances are some of them would not hold true today. For example, (1) that women -traditionally- place more importance on colour than men (Lakoff, 1973; Gekousidou \& Iliadou, 1997) due to their lower position in society and their interests in cosmetics, clothing and fashion, house décor, jewellery, etc., whereas men underperform owing to their powerful positions in society and being uninterested in rather shallow matters as colours (Lakoff, 1973). In fact, women's advanced colour lexicon is considered to be trivial, hence, relegating and downgrading this proficient use of language by women (Gekousidou \& Iliadou, 1997). Therefore, colour exposition through profession and day-to-day activities plays an important part in colour lexicon. This is exemplified by Ling et al. (2007) that mentions women gatherers needing a better colour discrimination to grab ripe fruits from trees than males, who were simply hunters.

Despite all this, it must be borne in mind the progress achieved since those studies were performed. Women have remarkably improved their position in society in the last 50 years (UN Women, 2018). Their presence in government and political positions is steadily increasing, as well as their access 
to traditionally male-dominated professions (Liu, 2020) ${ }^{4}$. Additionally, colour-related professions are increasing as a result of innumerable technological advances and a higher exposure to art in its many different forms is experienced thanks to the Internet. Thus, it is only natural that these contextual variables might be balancing the traditional gender differences explained previously (section 3).

Apart from that, (2) fine colour discrimination, that is, the active use and identification of a vast number of colour terms beyond BCTs, is associated to femaleness and even derogatory when applied to a man, as it can «damage» their reputation due to stereotyped and preconceived ideas (Lakoff, 1973, p. 52; Gekousidou \& Iliadou, 1997, p. 96). McConnel-Ginet (1980, p. 16) also adds the fear of backlash and homophobia as a reason for male avoidance of proficient colour terminology. It is still left to analyse if younger generations are fully conscious of the prejudices behind of such stereotyped assumptions.

Furthermore, (3) Saucier et al. (2002) suggest females excelling in colour naming as a result of their inherent larger colour lexicons, speed at naming things in general -and, consequently, also in colour naming-, superior motor sequencing ability and articulatory speed, and superiority in visual scanning tasks. The conclusions reached for quicker female response are twofold: superior access to colours and shape lexicon, that is, label retrieval (naming factor) or superior articulation and production of names (motor sequencing factor). Likewise, Elias et al. (2003, p. 960) indicate «female advantage for speeded naming tasks is due to advantage for sequencing the oral movements required for the response, rather than a special 'naming ability'».

Additionally, (4) Steckler \& Cooper (1980) ascribe different developmental colour terminology acquisition during childhood as a possibility for said differences. Nevertheless, these linguistic differences cannot be attributed to dissimilarities in the transmission of colouristic information at a young age but to contextual aspects, like expressiveness and appropriateness within a specific context and culture (Labov, 1972).

Lastly, (5) experiential and/or socio-cultural factors, such as age, gender, education level, social contact, social status, one's interests or hobbies may

4. That being said, we are cognizant of the many efforts yet to be made to achieve real gender equality. 
be the underlying reason for gender differences and not physiological or biological factors (Swaringen et al., 1978; Simpson \& Tarrant, 1991; Greene \& Gynther, 1995; Yang, 1996; Gekousidou \& Iliadou, 1997; Mylonas \& Macdonald, 2012, p. 258). In fact, Labov (1972, p. 240) found lower middle-class females are more sensitive to prestige forms than males because of their constant need to secure their social status through their linguistic capabilities.

In summary, this section has analysed a number of plausible causes for gender dissimilarities in colour lexicon. The next part will tackle objectives of the present study.

\section{AIMS OF THIS STUDY}

The main objective of this study is to determine and measure whether there is any significant difference in colour term production in Spanish university students. The focus, therefore, lies on the participants' mental lexicon and production when exposed to colour stimuli. That is, the focus is placed on any difference in richness in term production rather than studying perception precision or promptness in production or response.

In addition, likelihood of metonymic colour term usage is analysed via Likert scale and open-ended questions to test prevalence and whether or not certain metonymic colour terms could be considered strictly female colour terms only. The intent is to shed some light on Nowaczyk's (1982, p. 264) affirmation that «women more than men have divided their internal color space into more distinct internal representations each with a corresponding verbal label» and determine whether this happens in Spanish participants as well ${ }^{5}$. Finally, the consistency of the responses and likelihood of repetition of terms in describing the selection is also tested, as it is also indicative of proficiency (Rich, 1977).

5. Generalisations regarding colour lexicon disposition should not be made, as cultural context plays an important part as a variable in lexicon construction. However, studies conducted in English in Western societies conclude that women use fancier colour terms. 


\section{METHODOLOGY}

\subsection{Participants}

A total of sixty-three undergraduate students took part in the experiment, 39 females (62\%) and 24 males (38\%), with an average age of 22 years. It is a homogeneous group of students, without any known colour blindness, currently studying English language and literature. Their sexual orientation is mostly heterosexual (70\%), but also bisexual (13\%), homosexual (11\%), asexual (2\%) and pansexual $(2 \%)^{6}$. Lastly, $2 \%$ did not specify their sexual orientation $^{7}$. All participants spoke Spanish as their mother tongue and $11 \%$ of them ( $8 \%$ of females and 3\% of males) also Catalan.

\section{Figure 1}

Sexual orientation and gender

Males

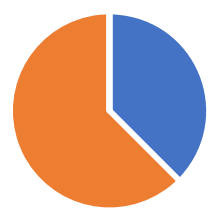

- LGBTQIA+ " Hetero - Unspecified
Females

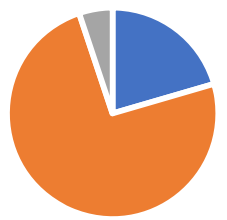

- LGBTQIA+ " Hetero $=$ Unspecified

\subsection{Test}

The study was performed using an online Google Forms questionnaire consisting of three parts (personal data, colour naming test, likelihood of MCT usage) during the months of June and July 2020.

6. The latter $28 \%$ are referred to as LGBTQIA+ community in the analysis below.

7. Their answers are not taken into account in analysis 7.3 as they cannot be attributed to any sexual orientation. 


\subsubsection{First section: personal data}

The participants' personal data is of great interest in determining possible gender differences. Thus, requirements to fill in data regarding nationality (Spanish native speakers), educational level, age, gender, sexual orientation and colour experience through colour-related hobbies (e.g. arts and painting, makeup, embroidery, fashion and clothing, hair dyes, interior decoration, photography and edition of pictures, graphic design, cinematography, the automobile industry, etc.) is indicated.

Although rather intrusive, participants are asked about their sexual orientation to test the affirmation made by Lakoff (1973, p. 49) that homosexual men demonstrate a better colour vocabulary range: «if the man should say (the colour mauve), one might well conclude he was either imitating a woman sarcastically, or a homosexual, or an interior decorator». Hence, colour terms like beige, aquamarine or lavender are typical and/or expected of a women's vocabulary but mostly absent in heterosexual men, according to Lakoff (1973).

As the participants are educated students, an acceptable knowledge of colour terms is expected across genders, even though they are not specialist in the field. Thus, differences, if any, should be more apparent in such homogenous sample group. Students are also asked about their leisure activities by giving them several colour-related hobby options and including an additional option to fill in with any other possible choices.

\subsubsection{Second section: colour elicitation}

In order to ensure consistent lighting conditions among all participants, instructions to adjust the screen brightness are given so as to set the highest brightness value in the chosen device. The main task consists in naming a series of colour stimuli presented in small coloured rectangles ${ }^{8}$ displayed against a neutral background. Thus, colour distortions originated from hue pairing do not affect perception (Rosenholtz, 2004). Additionally, the sequential presentation of colours was done through plain colour pictures and not through pictures of coloured objects or allusion to particular scenarios (e.g.

8. Updated lighting-controlled version of the traditional colour naming chips. 
indication to describe a colour as if describing it to a salesperson (Rich, 1977)) to prevent further bias. Otherwise, this may influence the participants' response into either producing a more elaborate and ad hoc chromatic terminology typical of advertising, or towards a colour denomination based on (fe)male clothing (Frank, 1990).

When devising the methodology of this experiment, limiting the response time was considered much like in previous studies (Simpson $\&$ Tarrant, 1991). The premise behind this limitation is to avoid the temptation of retrieving obscure names that would not be salient or natural in ordinary speech. Ultimately, we opted for no time limit to prevent participants from anxiously responding brief and general responses. The present study is not concerned with fastness of response but rather with colour name production in eliciting tasks and how (dis)similar the responses are according to gender. Consequently, instructions to be precise without overthinking are given to ensure spontaneity, but no time limit is established. In addition, this experiment is unconstrained: any given response is valid as long as it assigns a linguistic label to the exposed colour stimuli. Responses may be from monolexemic up to highly descriptive compounds containing three or more words.

Our selection includes thirty-five colour stimuli retrieved from the Pantone's ${ }^{9}$ webpage, nine of which -roughly the $25 \%$ of the sample-could be classified as BCT. When handpicking the colours ${ }^{10}$, hue over-repetition was avoided by selecting several hues from the colour spectrum, that is, the eleven BCTs and diverse in-between macro-category hues. Instructions to name the colour perceived are given without further indications to obtain true spontaneous and unconstrained responses.

9. Although not an organising colour system per se as the Munsell System and others are, Pantone is a well-known colour-specification and standardisation system for printing ink. Their «universal language», as they call it, was created in 1963 with 500 colours and was increased as the years went by, to reach over 1300 colours by 2010 .

10. Only the colour representation was shown in the test. The Pantone colour name and Hex/HTML value is only included in Table 1 for informative purposes. 
Table 1

Colours tested

\begin{tabular}{|c|c|c|}
\hline Pantone name & Representation & Hex/HTML \\
\hline Bright White & & F4F9FF \\
\hline Vanilla Cream & & F5D8C6 \\
\hline Peach Fuzz & & FFBE98 \\
\hline Salmon & & FAAA94 \\
\hline Cocoa Brown & & $6 C 5042$ \\
\hline Mahogany & & $824 \mathrm{D} 46$ \\
\hline Tan & & B69574 \\
\hline Red Dahlia & & 7D2027 \\
\hline Pantone 207 C & & A 50034 \\
\hline True Red & & BF1932 \\
\hline Spicy Orange & & D73D26 \\
\hline Orange & & FE5000 \\
\hline Yolk Yellow & & E2B051 \\
\hline Wax Yellow & & EDE9AD \\
\hline Lemon & & F3BF09 \\
\hline Dark Blue & & 00249C \\
\hline Navy Blue & & $403 \mathrm{~F} 6 \mathrm{~F}$ \\
\hline
\end{tabular}

Feminismo/s 38, July 2021, 115-147 


\begin{tabular}{|c|c|c|}
\hline Deep Periwinkle & & 7C83BC \\
\hline Sky Blue & & 8ABAD3 \\
\hline Turquoise & & 45B5AA \\
\hline Pantone 2272 C & & 009A17 \\
\hline Pantone $2411 \mathrm{C}$ & & $1 C 4220$ \\
\hline Grass Green & & 9FAF6C \\
\hline Green Olive & & 8D8B55 \\
\hline Violet & & 440099 \\
\hline Plum & & 5A315D \\
\hline Mauve Mist & & C49DB4 \\
\hline Lavender & & AFA4CE \\
\hline Pantone $241 \mathrm{C}$ & & AF 1685 \\
\hline Pink C & & D62598 \\
\hline Romance Rose & & E8B4C2 \\
\hline Stone Gray & & $685 \mathrm{E} 4 \mathrm{~F}$ \\
\hline Cool Grey 9 C & & $75787 \mathrm{~B}$ \\
\hline Graphite & & 3B3B48 \\
\hline Black 6 C & & 101820 \\
\hline
\end{tabular}

Feminismo/s 38, July 2021, 115-147 
The majority of colours selected already have a label, a name, provided by the company Pantone, whereas some others only have an alphanumeric reference. The labels provided by Pantone include modified BCTs, either by lightness and saturation modifiers (e.g. bright white, dark blue), MCTs (e.g. salmon, lavender), MCTs + BCTs (e.g. wax yellow), and anaphoric evocative terms (e.g. mauve mist, romance rose) with marketing intent. Although the aim of this experiment is not to test whether the students match their names to the ones provided by Pantone, some Pantone colours were selected for this test owing to the name given to them (e.g. mauve, turquoise), which are particularly interesting for the study, to compare with Lakoff's (1975) results.

The colour terms provided by participants are grouped into three main categories: (1) BCTs (Berlin \& Kay's, 1969); (2) Qualified, if further hue, saturation and lightness specifications are provided (e.g. adjectives referring to lightness and saturation, such as light, dark, intense, vivid, deep, pale; mixed hues by means of dvandva compounds (red-orange, blue-green), derived compounds (e.g. reddish-brown, bluish green), derivative forms (e.g. orangey), modified derivative compounds (e.g. light reddish-brown, pastel greyish-blue) and prototypicality modifications (true red, classic red). (3) MCTs, working on their own (e.g. turquoise, emerald, cream), modified by adjectives (e.g. dark beige, light salmon, dark lilac), followed by a BCT (e.g. turquoise blue, emerald green), or even the combination of all the previously mentioned categories (e.g. dark forest green, pastel military green, dull mustard yellow), MCT+MCT compounds (e.g. cream beige) and derivative compounds, being the derived element a MCT (e.g. beigy pink), or the BCT (e.g. reddish maroon).

In order to measure response consistency, one colour (sky blue), is repeated twice in the questionnaire. Participants are not informed about the repetition, which is properly separated by 34 colour samples (i.e. first shown in question 2 and then in question 36). All subjects were presented the colours in the same order.

\subsubsection{Third section: MCT usage probability}

After the elicitation task, likelihood of usage of eight MCTs is implemented by means of a Likert scale, being 1 very unlikely and 5 highly likely. The MCTs selected (i.e. chocolate, lila, turquesa, limón, malva, ocre, salmon y 
carne $^{11}$ ) belong to some of the most common categories within MCTs: food and beverages, flowers and plants, dyes and pigments, animals and minerals. Turquoise and lilac were chosen, as Mylonas and Macdonald's (2016, p. 40) study suggests the possible extension of the traditional eleven BCTs in English with their incorporation. Therefore, we wanted to test the probability of usage and identification through stimuli of those two particular colour terms, to determine whether or not these terms showcase saliency in Spanish-speaking participants. In addition, although being fairly similar colours, lilac and mauve were selected to test Lakoff's (1973) affirmation that mauve is an eminently female colour term. With respect to flesh, it was chosen because of its problematic nature when it comes to inclusivity and diversity (Dawson, 2016) and its possible switch for the euphemistic anglicism nude, extensively utilised in the fashion and beauty realm (Diez-Arroyo, 2016). Finally, lemon, chocolate and ochre were selected as they are relatively transparent metonymic terms, semantically speaking.

\section{RESULTS AND DISCUSSION}

The results gathered include participants interests and hobbies (section 7.1 $1^{12}$ ), the elicitation task results (section 7.2) and likelihood of MCT substitution by other terms and reasons behind it (section 7.3).

\subsection{Personal data}

Similar to Simpson and Tarrant (1991) and Greene and Gynther (1995) results when it comes to hobbies, females displayed a higher array of colour-related hobbies ${ }^{13}$. Although both males and females indicate a high percentage of colour-related interests ( $91.6 \%$ and $92.3 \%$, respectively), there are differences in the number of hobbies selected per person: females selected an average of 2.23 hobbies, whereas males an average of 1.54 .

11. In English chocolate, lilac, turquoise, lemon, mauve, ochre, salmon and flesh.

12. The rest of personal data can be found in section 6.1.

13. Namely, beauty (comprising make-up and hair colour), fashion, photography (including video and image edition), automobiles, art (paintings, paint), graphic design, and others. 
Table 2

Hobbies per gender

\begin{tabular}{ccccccccc}
\hline & Beauty & Fashion & Photography & Automobiles & Art & Graphic Design & Others & Total \\
\hline F & 21 & 23 & 15 & 0 & 26 & 3 & 0 & 88 \\
& $(24 \%)$ & $(26 \%)$ & $(17 \%)$ & & $(30 \%)$ & $(3 \%)$ & & $(100 \%)$ \\
\hline M & 5 & 5 & 8 & 5 & 5 & 4 & 4 & 36 \\
& $(14 \%)$ & $(14 \%)$ & $(22 \%)$ & $(14 \%)$ & $(14 \%)$ & $(11 \%)$ & $(11 \%)$ & $(100 \%)$ \\
\hline
\end{tabular}

Principally, females indicate various colour-related hobbies (art, beauty and fashion being the primary ones), which in combination with other variables may ultimately influence colour lexicon and vocabulary proficiency.

\subsection{Colour elicitation}

The differences in colour production, especially in BCTs and MCTs, are not as prominent as in previous studies. If anything, a predilection for qualified colour terms is felt in males, whereas females turn mainly to BCTs and/or MCTs.

Table 3

Colour elicitation results

\begin{tabular}{rcccc}
\hline & \multicolumn{2}{c}{ Females } & \multicolumn{2}{c}{ Males } \\
\hline & $\mathrm{n}$ & $\%$ & $\mathrm{n}$ & $\%$ \\
\hline BCT & 519 & $38 \%$ & 294 & $35 \%$ \\
\hline Qualified & 273 & $20 \%$ & 218 & $26 \%$ \\
\hline MCT & 573 & $42 \%$ & 328 & $39 \%$ \\
\hline Total & 1365 & $100 \%$ & 840 & $100 \%$ \\
\hline
\end{tabular}

As far as BCT production is concerned, it is fairly similar in both sexes with slightly more than a third of colour term production (38\% females, 35\% males) and coincidence on the most prevalent ones (green, brown and blue). 
Figure 2

BCT usage

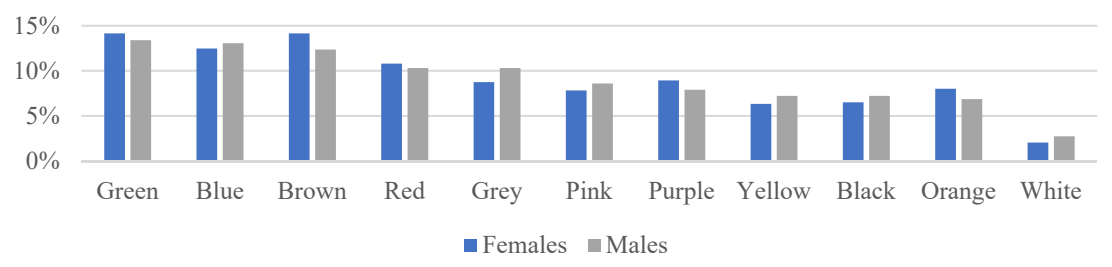

Insofar as the use of qualified terms in our study goes, males are far more reliant on qualified colour terms than females (20\% females, $27 \%$ males) and premodification with lightness and saturation adjectives is markedly predominant (dark blue, dull purple). In mixed hue production, males also combine it with premodification (deep reddish brown, light pastel blue, bluish dark grey) when females do not. Interestingly, uninformative premodifications only occur in male production with the presence of adjectives which fail to identify the hue further than acknowledging no prototypicality (weird black, weird purple) or even errors. ${ }^{14}$

\section{Table 4}

Qualified term production

\begin{tabular}{lcccccc}
\hline & \multicolumn{3}{c}{ Females } & \multicolumn{3}{c}{ Males } \\
\hline & n & Qua \% & Total \% & n & Qua \% & Total \% \\
& & & & & & \\
\hline Premodification & 169 & $62 \%$ & $12 \%$ & 128 & $59 \%$ & $15 \%$ \\
\hline Mixed hue & 104 & $38 \%$ & $8 \%$ & 74 & $34 \%$ & $9 \%$ \\
\hline Premodifier + mixed hue & - & - & - & 9 & $4 \%$ & $1 \%$ \\
\hline Other combinations & - & - & - & 7 & $3 \%$ & $1 \%$ \\
\hline Total & 273 & $100 \%$ & $20 \%$ & 218 & $100 \%$ & $26 \%$ \\
\hline
\end{tabular}

14. Rosa palo is a colour term equivalent to pale pink, that comes from the colour of the wood from a tree commonly known as 'palo (de) rosa' (mainly from the bignoniaceae or fabaceae family) when it is tender before drying («Palo de rosa», 2020). There are two instances produced by males (marron palo and morado palo) where 'palo' is used as a modifier indicating a paler hue. 
Despite the many compound combinations that may occur in this section, premodifications with the adjective dark seem to be the most prevalent (e.g. dark blue, dark grey).

Figure 3

Most prevalent qualified terms

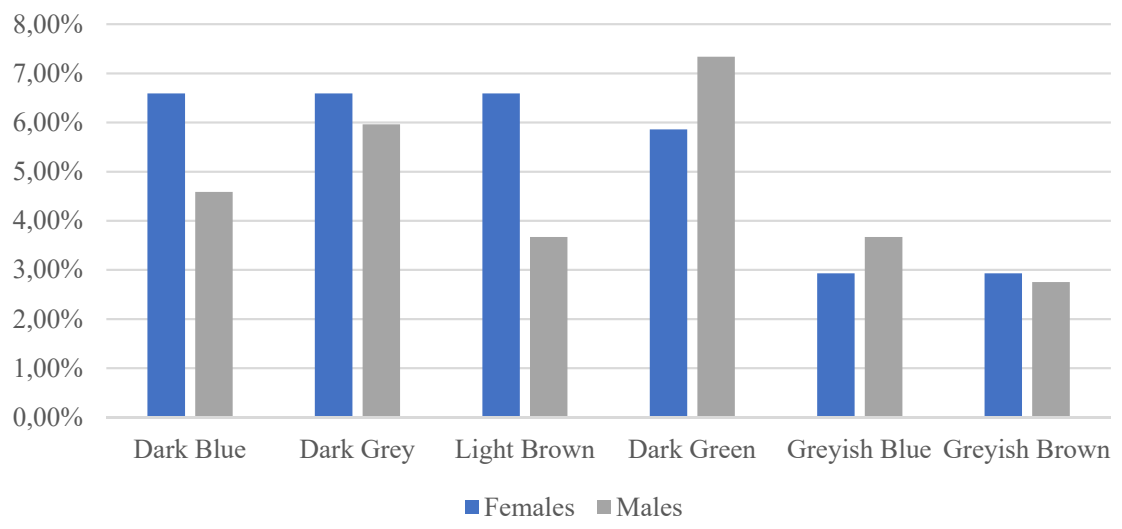

Thirdly, although males produce more isolated MCTs in proportion to females (see table 5), females utilise more MCTs altogether (42\% vs 39\%), through modifications and combinations (see table 3). Apart from that, females displayed higher MCT variation with up to 59 different terms, whereas males only produced 53. These results are similar to Nowaczyk's (1982) in his second experiment, where elaborate colour term description showed equal BCT usage across genders, but more quantity and elaboration in female descriptions. 
Table 5

Atomised MCTs

\begin{tabular}{|c|c|c|c|c|c|c|}
\hline & \multicolumn{3}{|c|}{ Females } & \multicolumn{3}{|c|}{ Males } \\
\hline & $\mathrm{n}$ & MCT \% & Total \% & $\mathrm{n}$ & MCT \% & Total \% \\
\hline MCTs & 347 & $61 \%$ & $25 \%$ & 221 & $67 \%$ & $26 \%$ \\
\hline $\mathrm{MCT}+\mathrm{BCT}$ & 144 & $25 \%$ & $11 \%$ & 66 & $20 \%$ & $8 \%$ \\
\hline $\mathrm{PRE}+\mathrm{MCT} / \mathrm{MCT}+\mathrm{MCT}$ & 76 & $13 \%$ & $6 \%$ & 38 & $12 \%$ & $5 \%$ \\
\hline $\begin{array}{l}\mathrm{ADJ}+\mathrm{MCT}+\mathrm{MCT} \\
\mathrm{ADJ}+\mathrm{ADJ}+\mathrm{MCT}\end{array}$ & 6 & $1 \%$ & $0 \%$ & 3 & $1 \%$ & $0 \%$ \\
\hline Total & 573 & $100 \%$ & $42 \%$ & 328 & $100 \%$ & $39 \%$ \\
\hline
\end{tabular}

On the whole, lilac appears as the most prominent MCT, which corresponds with one of the few non-basic terms making their way towards basicness (Mylonas \& Macdonald, 2016). Even though both lilac and mauve are similar MCTs (both in reference to hue and the nature of the metonymy, as both refer to flowering plants), the saliency of mauve is extremely low both in males and females $(0,48 \%$ and $0,95 \%$, respectively) and it is dramatically outweighed by lilac ( $5,42 \%$ females, $4,05 \%$ males). That being said, females almost double the use of mauve when compared to males.

On the contrary, turquoise, the other non-basic potentially able to reach BCT status (Mylonas \& Macdonald, 2016), is in the seventh position in female production and ninth in male production. This ranking could possibly be attributed to the variety of quasi-synonyms of the term (e.g. aquamarine, aqua green), or the presence of turquoise accompanied by BCTs (e.g. 9 instances of turquoise blue in total, and 2 of turquoise green), whereas lilac never collocates with BCTs. Furthermore, flesh and nude are evenly distributed in female use, while males tend adopt flesh over nude. 
Figure 4

Most prevalent MCTs

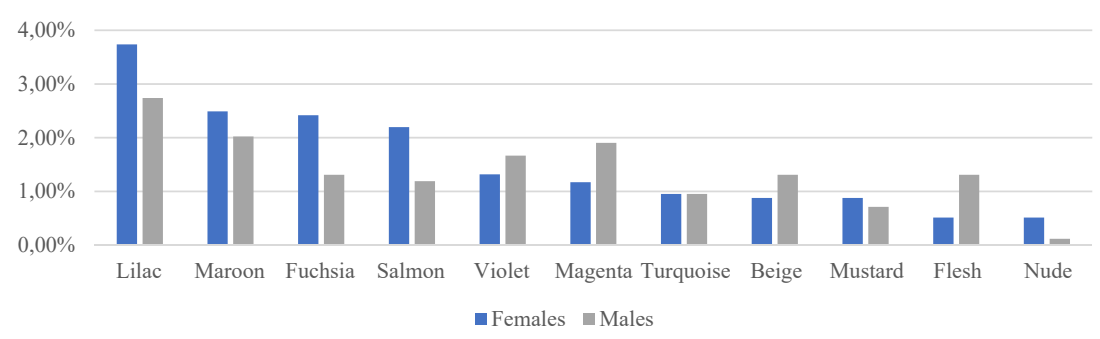

Within MCT production, apart from those that work alone, the ones followed by BCT have been isolated, as well as the ones modified by lightness and saturation adjectives. The former showcases navy blue, sky blue and mustard yellow as very prominent collocations in both sexes.

Figure 5

Most prevalent MTCs + BCTs

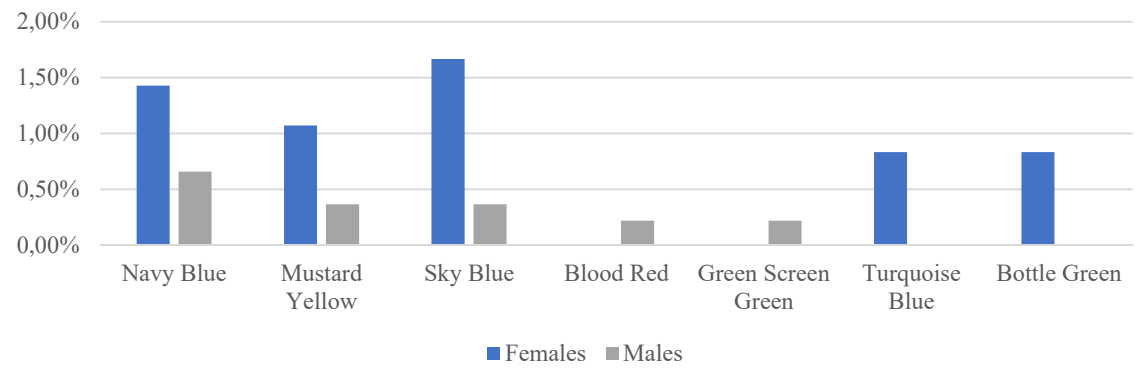

The latter evidences highly diverse and specific answers: modified MCT (with or without BCT), as in dark mustard (yellow); or mixed hue of BCT+MCT, as in pink beige. Despite the very varied answers, lilac combinations (e.g. light, dark, pastel) are the most prevalent. This points to its salience in Spanish, in line with what Mylonas and Macdonald (2016, p. 40) mentioned in English. 
Table 6

Most prevalent modified MCTs

\begin{tabular}{lccccc}
\hline & Dark Lilac & Light Lilac & Pastel Lilac & Dull Mustard Yellow & Dark Magenta \\
\hline F & $15 \%$ & $13 \%$ & $8 \%$ & $5 \%$ & - \\
\hline M & $8 \%$ & $13 \%$ & $8 \%$ & - & $13 \%$ \\
\hline
\end{tabular}

Finally, response consistency was tested by including a repeated coloured image in different places across the questionnaire, far enough from each other so as to be unnoticeable. Although higher specificity is felt in both sexes as the questionnaire progresses -that is, higher prevalence of BCTs at first and, as the test progresses, more specificity offered to differentiate hues-, females exhibit more specificity changes than males. In the first instance of light blue, females score 67 points and males 42 points, whereas the second time around they score 89 and 52, correspondingly ${ }^{15}$. This further reinforces how males prefer consistency and females favour variety.

\subsection{Likelihood of MCT usage}

After the elicitation task, a Likert scale was used for participants to determine what their degree of MCT usage is. In all the MCTs tested, females showcase -or rather, felt- a higher percentage of usage. In other words, females feel more open to using MCTs than males.

\section{Table 7}

Probability of MCT usage

\begin{tabular}{lrrrrrrrr}
\hline & Chocolate & Lilac & Turquoise & Lemon & Mauve & Ochre & Salmon & Flesh \\
\hline $\mathrm{F}$ & $62 \%$ & $90 \%$ & $85 \%$ & $53 \%$ & $51 \%$ & $52 \%$ & $76 \%$ & $53 \%$ \\
\hline $\mathrm{M}$ & $46 \%$ & $73 \%$ & $73 \%$ & $41 \%$ & $39 \%$ & $43 \%$ & $60 \%$ & $52 \%$ \\
\hline
\end{tabular}

Interesting data is revealed in table 7, where lilac and turquoise display a high prevalence when compared to the other colours in the study in both males and females. Flesh is identified as problematic by $10 \%$ of the participants when asked if they would substitute some MCT by other terms. They deem

15. This is done by giving one point to BCTs, two points to qualified and three, four and five points to MCTs, MCTs + BCTs and modifications of MCTs. 
it as incorrect rather than imprecise, as flesh is traditionally confined to light coloured skin rather than with any skin tone. Thus, it is possible that the awareness of the problematic is preventing usage. Nonetheless, should flesh acquire a more inclusive approach in the near future, hue precision would be lost altogether. Generally, ochre, lemon and mauve register a lower incidence, being mauve one the lowest in both sexes. However, if we break down data according to sexual orientation, the LGBTQIA+ community outperform in all categories except for flesh, where heterosexual female's usage prevails.

\section{Table 8}

Probability of MCT usage according to sexual orientation and gender

\begin{tabular}{lcccc}
\hline & \multicolumn{2}{c}{ Females } & \multicolumn{2}{c}{ Males } \\
\cline { 2 - 5 } & Hetero & LGBTQIA+ & Hetero & LGBTQIA+ \\
\hline Chocolate & $59 \%$ & $75 \%$ & $43 \%$ & $51 \%$ \\
\hline Lilac & $88 \%$ & $100 \%$ & $67 \%$ & $87 \%$ \\
\hline Turquoise & $81 \%$ & $100 \%$ & $63 \%$ & $93 \%$ \\
\hline Lemon & $50 \%$ & $68 \%$ & $40 \%$ & $44 \%$ \\
\hline Mauve & $49 \%$ & $60 \%$ & $36 \%$ & $49 \%$ \\
\hline Ochre & $47 \%$ & $78 \%$ & $44 \%$ & $44 \%$ \\
\hline Salmon & $74 \%$ & $88 \%$ & $59 \%$ & $71 \%$ \\
\hline Flesh & $53 \%$ & $48 \%$ & $53 \%$ & $60 \%$ \\
\hline
\end{tabular}

Apart from the Likert scale previously mentioned, three open unconstrained questions related to the MCTs tested previously were asked to enquire about the reason behind their use of the aforementioned MCTs or lack thereof. Answers can be ordered according to favourable attitudes (precision, social conventions, contextual exposure and preferable terms) or unfavourable attitudes towards MCT use (lack of knowledge, other term preferences or no use whatsoever). What stands out in Table 9 is the high percentage of males providing argumentations against MCT use (45\%): $29 \%$ of males admitted a lack of knowledge, either of the real hue term or lack of force of habit with metonyms. Paradoxically, it seems as metonymic precision and specificity is dismissed in favour of qualified colour terms, that is, males rather step back and be more general so the main hue remains unambiguous. For instance, 
salmon is more specific, short and concrete than light pink, as it denotes the mixture of two hues: orange and pink. In fact, other MCTs could be comprised within light pink, such as bubble gum (pink), cotton candy (pink), among others. On the contrary, mixed hues such as orange-pink, pinkish orange or orangey pink could be considered closer to salmon, although dissimilar among themselves depending on the head of the compound. Additionally, $8 \%$ acknowledge no MCT usage whatsoever and $8 \%$ disclose a preference for qualified BCTs (referring to saturation and lightness) as they deem them more common and unambiguous.

From the $55 \%$ males favourable to MCTs, $21 \%$ recognise the convenience of signalling coloured foci, $17 \%$ mention precision and $13 \%$ indicate exposure through influence of relatives or their inner circle colour experts (e.g. grandmother that worked in the fashion industry, graphic designers). Lastly, only a $4 \%$ attribute their usage to social conventions and tradition. In conclusion, males regard their MCT elicitation rather poorly when, in actuality, their performance is not as deficient. These findings complement Nowaczyk's (1982, p. 261), who mentioned men actively refusing to use MCTs in the matching task in favour of BCTs.

\section{Table 9}

Answers to question 1

\begin{tabular}{|c|c|c|c|c|c|c|c|c|}
\hline \multirow[t]{2}{*}{ Q1 } & \multicolumn{4}{|c|}{ Favourable attitude towards MCTs } & \multicolumn{3}{|c|}{ Unfavourable attitude towards MCTs } & \multirow[t]{2}{*}{$\varnothing$} \\
\hline & Social convention & Precision & Exposure & $\begin{array}{l}\text { Prefer } \\
\text { MCT }\end{array}$ & No use & Lack knowledge & $\begin{array}{c}\text { Prefer } \\
\text { other }\end{array}$ & \\
\hline \multirow[t]{2}{*}{ M } & $4 \%$ & $17 \%$ & $13 \%$ & $21 \%$ & $8 \%$ & $29 \%$ & $8 \%$ & $0 \%$ \\
\hline & \multicolumn{3}{|c|}{$55 \%$} & \multicolumn{4}{|c|}{$45 \%$} & \\
\hline \multirow[t]{2}{*}{ F } & $8 \%$ & $23 \%$ & $15 \%$ & $31 \%$ & $0 \%$ & $5 \%$ & $3 \%$ & $15 \%$ \\
\hline & \multicolumn{3}{|c|}{$77 \%$} & \multicolumn{5}{|c|}{$8 \%$} \\
\hline
\end{tabular}

In contrast, an overwhelming majority of females (77\%) is favourable to MCT use, whereas only $8 \%$ are reluctant to them. It is important to highlight that from that minority, only 5\% admit a lack of knowledge and 3\% prefer other terms. Overall, females recognise MCTs' convenience (31\%), precision, specificity and ability to provide lexical variation (23\%). Additionally, 15\% of females indicate acquisition through exposure to specific contexts (makeup and the fashion industry). 
The second question referred to whether or not MCTs are necessary in everyday speech. The results match our previous gathered data: the tendency is to consider them necessary to better convey colour precision ( $72 \%$ females, $50 \%$ males). Metonymic terms offer more exactitude, detail and meticulousness when making reference to a focal point related to a real object (e.g. ivory instead of light yellow) and achieve maximum disambiguation and overall better understanding. This richness in variation is deeply appreciated by females that resort to them more frequently, reason that would motivate gender differences in use. In fact, males tend to substitute MCTs more (25\% of males versus $10 \%$ of females) and only men consider them unnecessary (8\%). Lastly, both genders acknowledge metonymic colour terms not being indispensable but convenient roughly in the same percentage (13\% and 15\%), that is, admit metonymic colour terms not being strictly necessary, as they can be substituted by others, but being useful in certain specific contexts.

Table 10

Answers to question 2

\begin{tabular}{lcrcrc}
\hline Q2 & $\varnothing$ & Yes & Substitution & No & Context \\
\hline $\mathrm{M}$ & $4 \%$ & $50 \%$ & $25 \%$ & $8 \%$ & $13 \%$ \\
\hline $\mathrm{F}$ & $3 \%$ & $72 \%$ & $10 \%$ & $0 \%$ & $15 \%$ \\
\hline
\end{tabular}

Finally, the last question inquired to what alternatives they resort to, should they refuse MCT usage. This question is employed to further reinforce the results previously obtained, as a way of consistency proof analysis: just over half of females do not substitute MCTs, whereas 30\% tend to use either BCTs, qualified or both. Conversely, a minority $17 \%$ of males do not substitute, while a $62 \%$ do substitute them by BCTs, qualified, a combination of both or alphanumeric terminology.

Table 11

Answers to question 3

\begin{tabular}{lcccccc}
\hline Q3 & $\varnothing$ & BCT & Qualified & BCTS and qualified & Alphanumeric & Do not substitute \\
\hline M & $21 \%$ & $21 \%$ & $33 \%$ & $4 \%$ & $4 \%$ & $17 \%$ \\
\hline F & $18 \%$ & $5 \%$ & $10 \%$ & $15 \%$ & $0 \%$ & $51 \%$ \\
\hline
\end{tabular}


In consequence, the results point to more categorisations and «internal representations $»^{16}$ (Nowaczyk, 1982, p. 264) in females. To conclude, regardless of MCT attitudes, MCT production is not felt as dissimilar as in the past, which leads to believe that, amongst other reasons, society's progress is levelling colour exposure and, in turn, people's colour lexicon.

\section{CONCLUSIONS}

This study set out to revisit and update previous colour studies and to analyse whether or not traditional gender differences still persist. Consistent with previous research studies (Swaringen et al., 1978; Steckler \& Cooper, 1980; Simpson \& Tarrant, 1991; Mylonas et al., 2014), females outperform males in MCT production and richness in colour vocabulary, although differences are not as striking as in the past. Possible reasons behind this may be derived from technological advantages, as, for example, increased colour term exposure and access to unfathomable information through the Internet, as well as age being an important factor in the reduction in the colour production differences and a more equal and balanced colour specific terminology.

Nonetheless, some differences are maintained, like female predilection for MCTs and more colour-related hobbies which could ultimately instil them with a much richer colour vocabulary (Swaringen et al., 1978; Simpson $\&$ Tarrant, 1991; Greene \& Gynther, 1995; Yang, 1996). Likewise, the male tendency to express internal representations with wider categories persists, specifically with saturation and lightness adjectives (Swaringen et al., 1978; Steckler \& Cooper, 1980; Simpson \& Tarrant, 1991; Mylonas et al., 2014). In terms of MCT usage perception, males admit a poorer production when, all things considered, it does not fall far behind females' production. Inherited and stereotyped cultural perceptions may be the reason behind this negative self-evaluation.

These findings suggest gender differences in colour naming still being prevalent but stabilising, at least in the context where this experiment was performed. Further research should be implemented in order to determine whether these findings could generalize or correlate to other groups of people

16. That is, a wider variety of mental colour gradations or depictions (e.g. vanilla, cream, buff, etc.) that could be subsumed under a hyperonym (e.g. yellow). 
beyond this limited sample of university students, in Spanish and other languages and cultures, with wider age sections and other areas of expertise. It would be specially interesting to further research on dissimilarities through the age variable and test if older participants present a more diverse colour vocabulary as a result of longer exposure and experience.

\section{REFERENCES}

Anishchanka, A., Speelman, D., \& Geeraerts, D. (2014). Referential meaning in basic and non-basic color terms. In W. Anderson, C. P. Biggam, C. Hough, \& C. Kay (Eds.), Colour studies: A broad spectrum (pp. 323-338). John Benjamins. https://doi.org/10.1075/z.191.21ani

Bergh, G. (2007). The semiosis of Swedish car color names: Descriptive and amplifying functions. In R. E. MacLaury, G. V. Paramei, \& D. Dedrick (Eds.) Anthropology of Color: Interdisciplinary Multilevel Modeling (pp. 337-346). John Benjamins. https://doi.org/10.1075/z.137.22ber

Berlin, B., \& Kay, P. (1969). Basic Color Terms: Their Universality and Evolution. University of California Press.

Biggam, C. P. (2012). The Semantics of Colour: A Historical Approach. Cambridge: Cambridge University Press. https://doi.org/10.1017/CBO9781139051491

Bonnardel, V., Miller, S., Wardle, L. \& Drews, E. (2002). Gender Differences in Colour-Naming Task. Perception 31 (Supplement): 71.

Brown, A. M., \& Lindsey, D. T. (2004). The color BLUE: The dictionary project. Journal of Vision, 4(8), 308. https://doi.org/10.1167/4.8.308

Casson, R. W. (1994). Russett, Rose, and Raspberry: The Development of English Secondary Color Terms. Journal of Linguistic Anthropology, 4(1), 5-22. https:// doi.org/10.1525/jlin.1994.4.1.5

Conklin, N. F. (1974). Towards a feminist analysis of linguistic behavior. The University of Michigan Papers in Women's Studies, 1(1), 51-73. http://hdl. handle.net/2027/spo.acp0359.0001.001:05

Dawson, A. (2016, July 14). What does the color «nude» mean now in an increasingly diverse world? Los Angeles Times. https://www.latimes.com/fashion/ la-ig-color-nude-20160622-snap-story.html

Diez-Arroyo, M. (2016). English words as euphemisms in Spanish fashion. English Today, 32(3), 30-39. https://doi.org/10.1017/S0266078416000043

DuBois, P. H. (1939). The Sex Difference on the Color-Naming Test. The American Journal of Psychology, 52(3), 380-382. https://doi.org/10.2307/1416747 
Elias, L. J., Saucier, D. M., Nylen, K., \& Cheesman, J. (2003). Female Advantage in Speeded Colour Naming: A Special Naming Factor or Superior Motor Sequencing? Perceptual and Motor Skills, 96(3), 955-961. https://doi. org/10.2466/pms.2003.96.3.955

Ellis, L., Hershberger, S., Field, E., Wersinger, S., Pellis, S., Geary, D., Palmer, C., Hoyenga, K., Hetsroni, A., \& Karadi, K. (2008). Sex Differences: Summarizing More than a Century of Scientific Research (1st ed.). Psychology Press.

Fider, N. A., \& Komarova, N. L. (2019). Differences in color categorization manifested by males and females: a quantitative World Color Survey study. Palgrave Communications, 5(1), 1-10. https://doi.org/10.1057/s41599-019-0341-7

Frank, J. (1990). Gender Differences in Color Naming: Direct Mail Order Advertisements. American Speech, 65(2), 114-126. https://doi. org/10.2307/455532

Gekousidou, S. \& Iliadou, N. (1997). Sex differences in colour naming. Selected Papers on Theoretical and Applied Linguistics, 11, 91-98. https://doi.org/10.26262/istal.v1li0.7032

Greene, K. S., \& Gynther, M. D. (1995). Blue versus Periwinkle: Color Identification and Gender. Perceptual and Motor Skills, 80(1), 27-32. https:// doi.org/10.2466/pms.1995.80.1.27

Hurlbert, A. C., \& Ling, Y. (2007). Biological components of sex differences in color preference. Current Biology, 17(16), 623-625. https://doi.org/10.1016/j. cub.2007.06.022

Hurlbert, A. C., \& Ling, Y. (2016). Understanding colour perception and preference. In Best, J., Colour Design: Theories and Applications (The Textile Institute Book Series) (1st ed.). Woodhead Publishing.

Kramer, C. (1974). Women's speech: Separate but unequal? Quarterly Journal of Speech, 60(1), 14-24. https://doi.org/10.1080/00335637409383203

Kuschel, R., \& Monberg, T. (1974). «We Don't Talk Much About Colour Here»: A Study of Colour Semantics on Bellona Island. Man, 9(2), 213-242. https:// doi.org/10.2307/2800075

Labov, W. (1972). Sociolinguistic Patterns. University of Pennsylvania Press.

Lakoff, R. (1973). Language and woman's place. Language in Society, 2(1), 45-80. https://doi.org/10.1017/S0047404500000051

Ligon, E. M. (1932). A Genetic Study of Color Naming and Word Reading. The American Journal of Psychology, 44(1), 103-122. https://doi. org/10.2307/1414958 
Lillo, J., González-Perilli, F., Prado-León, L., Melnikova, A., Álvaro, L., Collado, J. A., \& Moreira, H. (2018). Basic Color Terms (BCTs) and Categories (BCCs) in Three Dialects of the Spanish Language: Interaction Between Cultural and Universal Factors. Frontiers in Psychology, 9, 1-19. https://doi.org/10.3389/ fpsyg.2018.00761

Ling, Y., Hurlbert, A. \& Robinson, L. (2006). Sex differences in colour preference. In C. P. Biggam \& N. J. Pitchford (Eds.), Progress in Colour Studies Volume II. Psychological aspects (pp. 173-188). John Benjamins. https://doi. org/10.1075/z.pics2.15lin

Liu, J. (2020, March 8). 10 male-dominated jobs where women are joining the ranks the fastest. CNBC. https://www.cnbc.com/2020/03/06/10-male-dominatedjobs-where-women-are-joining-the-ranks-the-fastest.html

McConnel-Ginet, S. (1980) Linguistics and the Feminist Challenge. In S. McConnell-Ginet, R. Borker, \& N. Furman (Eds.), Women and Language in Literature and Society (pp. 3-26). Praeger Publishers.

Merskin, D. (2007). Truly Toffee and Raisin Hell: A Textual Analysis of Lipstick Names. Sex Roles, 56, 591-600. https://doi.org/10.1007/s11199-007-9201-9

Mioduszewska, M. (2014). Unfolding colour in mind and language: Strategies for colour denotation in Spanish wine-tasting notes. In W. Anderson, C. P. Biggam, C. Hough, \& C. Kay (Eds.), Colour studies: A broad spectrum (pp. 339-351). John Benjamins. https://doi.org/10.1075/z.191.22mio

Mylonas, D. \& L. Macdonald, L. (2012). Colour naming for colour communication. In J. Best (Ed.) Colour Design (pp. 254-270). Woodhead Publishing. https://doi.org/10.1533/9780857095534.2.254

Mylonas, D. \& Macdonald, L. (2016). Augmenting Basic Colour Terms in English. COLOR research and application, 41(1), 32-42. https://doi.org/10.1002/ col.21944

Mylonas, D., Paramei, G.V. \& MacDonald, L. (2014). Gender Differences in Colour Naming. In W. Anderson, C. P. Biggam, C. A. Hough, \& C. J. Kay (Eds.), Colour Studies. A Broad Spectrum (pp. 225-239). John Benjamins. https://doi.org/10.1075/z.191.15myl

Nowaczyk, R. H. (1982). Sex-Related Differences in the Color Lexicon. Language and Speech, 25(3), 257-265. https://doi.org/10.1177/002383098202500304

Obregón, H. (1978). Las denominaciones de colores y el enriquecimiento léxico. Boletín de Filología Universidad de Chile, 29, 201-218. https://boletinfilologia. uchile.cl/index.php/BDF/article/view/46648/48652 
Palo de rosa. (2020, March 21). In Wikipedia. https://es.wikipedia.org/wiki/ Palo_de_rosa

Pantone (n.d.). Find a Pantone Color, Quick Online Color Tool. Pantone. Retrieved October 1, 2020, from https://www.pantone.com/color-finder

Rich, E. (1977). Sex-related differences in colour vocabulary. Language and Speech, 20(4), 404-409. https://doi.org/10.1177/002383097702000411

Rosenholtz, R., Nagy, A. L., \& Bell, N. R. (2004). The effect of background color on asymmetries in color search. Journal of Vision, 4(3), 224-240. https://doi. org/10.1167/4.3.9

Saucier, D. M., Elias, L. J., \& Nylen, K. (2002). Are colours special? An examination of the female advantage for speeded colour naming. Personality and Individual Differences, 32(1), 27-35. https://doi.org/10.1016/S0191-8869(00)00234-8

Simpson, J., \& Tarrant, A. W. S. (1991). Sex- and Age-Related Differences in Colour Vocabulary. Language and Speech, 34(1), 57-62. https://doi. org/10.1177/002383099103400104

Skorinko, J. L., Kemmer, S., Hebl, M. R \& Lane, D. M. (2006). A Rose by Any Other Name...: Color-Naming Influences on Decision Making. Psychology E Marketing, 23(12), 975-993. https://doi.org/10.1002/mar.20142

Steckler, N. A., \& Cooper, W. E. (1980). Sex Differences in Color Naming of Unisex Apparel. Anthropological Linguistics, 22(9), 373-381. https://www. jstor.org/stable/30027797

Steinvall, A. (2002). English Colour Terms in Context. Institutionen för moderna språk, Univ.

Stoeva-Holm, D. (2007). Color Terms in Fashion. In R. E. MacLaury, G.V. Paramei, \& D. Dedrick (Eds.) Anthropology of Color: Interdisciplinary Multilevel Modeling (pp. 421-439). John Benjamins. https://doi.org/10.1075/z.137.28sto Swaringen, S., Layman, S., \& Wilson, A. (1978). Sex Differences in Color Naming. Perceptual and Motor Skills, 47(2), 440-442. https://doi.org/10.2466/ pms.1978.47.2.440

UN Women. (2018, July). Facts and Figures: Economic Empowerment. https://www. unwomen.org/en/what-we-do/economic-empowerment/facts-and-figures

Wyler, S. (1992). Colour and Language: Colour Terms in English. Gunter Narr Verlag.

Yang, Y. (1996). Sex- and level-related differences in the Chinese color lexicon. WORD, 47(2), 207-220. https://doi.org/10.1080/00437956.1996.11435954 